\title{
CORRESPONDENCIA DE JULIÁN RIBERA A PASCUAL MENÉU: UNA AMISTAD EN UNA ETAPA DECISIVA DEL ARABISMO (1899-1904)
}

\author{
Bernabé LÓPEZ GARCÍA \\ Universidad Autónoma de Madrid
}

La correspondencia es un género que presenta una utilidad complementaria para la reconstrucción histórica. Pero tiene la virtud de descubrirnos a los protagonistas de la historia en una actitud diferente a la que nos llega a través de sus publicaciones o discursos. Cuando la correspondencia es privada los personajes que se nos descubren lo hacen de una manera espontánea que nos permite conocer sus expansiones y aún algunos de sus secretos.

La correspondencia del arabismo español, tanto entre sí como con otros personajes, apenas si ha dado lugar a algunas publicaciones ${ }^{1}$, entre ellas una parte del prolífico intercambio entre el fundador de la escuela, Pascual de Gayangos y su extensa nómina de discípulos². Dicha correspondencia ha testimoniado acerca de la estrecha relación que ligara a Reinhardt Dozy con Francisco Javier Simonet, por ejemplo,

${ }^{1}$ Véanse los trabajos de M. Gómez Moreno, "Unas cartas de "El Solitario" ", en el Boletín de la Real Academia Española, XXXIII (1953), pp. 209-242, sobre la correspondencia de Estébanez Calderón con Francisco Javier Simonet, y de M. de Epalza, "Correspondencia del arabista mallorquín Artigas con el valenciano Borrull sobre historia árabe valenciana (1828-1829)", en Sharq al-Andalus. Estudios Arabes, 4 (Alicante 1987), pp. 235-239.

${ }^{2}$ Esta correspondencia fue estudiada por el autor de este articulo en su tesis doctoral: Contribución a la historia del arabismo español. Orientalismo y colonialismo en España 1840-1917, Universidad de Granada, 1973. Una parte apareció publicada en B. López García, "Cartas inéditas de Francisco Codera a Pascual de Gayangos (Reivindicación de una figura del arabismo)", Miscelánea de Estudios Árabes y Hebraicos, XXIV, 1 (Granada 1975), pp. 29-68, así como en "Orígenes del arabismo español. La figura de Francisco Fernăndez y González y su correspondencia con Pascual de Gayangos", Cuadernos de la Biblioteca Española de Tetuán, 19-20 (Tetuán 1979), pp. 277-306. 
o de la habilidad con que el propio Gayangos influye para asentar profesionalmente a una larga nómina de discipulos. Sin embargo, ciertas resistencias a permitir descubrir la privaticidad de estos documentos han impedido que se conozcan con más detalle las vicisitudes de la creación y desarrollo de la escuela de arabistas.

Por ello es de especial interés el dar a conocer algunos rasgos de la personalidad de los arabistas españoles a través de un corpus epistolar de sumo interés: la correspondencia recibida por Pascual Menéu y Menéu entre 1888 y 1907, de la que me hizo llegar fotocopia el hijo de aquél, Pascual Menéu y Monleón, con el expreso deseo de darlas a la luz. Se trata de un conjunto de 68 cartas entre las que dominan las de su maestro Francisco Codera (35 en total a lo largo de todo el período indicado), pero entre las que hay de Julián Ribera (17 entre 1899 y 1904), Pedro Roca (tres entre 1899 y 1902), Mariano Viscasillas (dos de 1900 y 1902), Miguel Asín (una de 1902), Fray Francisco María Cervera (una de 1902), Andrés Giménez Soler (seis de 1903-7), Nicolás Salmerón (una de 1903), Manuel Ferrandis (una de 1904) y Ramón Menéndez Pidal (una de 1906). De hecho sólo las correspondientes a Codera y Ribera tienen un sentido por sí mismas: las primeras, por ser las más numerosas y abarcar un período más amplio, así como por descubrirnos detalles de la personalidad y biografía del receptor de las cartas desde su estancia en Tánger para instalar la imprenta arábiga de la Misión Franciscana; las segundas, aunque sólo se trata de dieciséis ${ }^{3}$ y circunscritas a un período breve que va desde 1899 a 1904, traslucen rasgos vitales de Ribera en una etapa clave de su vida y de la historia del arabismo.

\section{La amistad entre Ribera y Menéu}

La relación de Julián Ribera con Pascual Menéu data de los años en que ambos colaboraron en la preparación de la edición de los tres primeros tomos de la Bibliotheca Arabico-Hispana entre 1882 y $1885^{4}$.

${ }^{3}$ A la que cabe añadir una más del hijo de Ribera incluida en una de su padre.

* Según testimonio de Pedro Roca, en carta a Pascual Menéu de 25 de 
Esta tarea, llevada a cabo en el propio domicilio de Codera, no consistió sólo en una labor de impresión, sino que fue una auténtica "escuela de árabe, privada y libre"s. Ribera y Menéu aprendieron todas las escalas de la tipografía árabe y se formaron en la erudición y el trabajo en equipo. De la amistad surgida en esos empeños dan testimonio estas cartas que ahora se publican. Es posible sin embargo que estos años no dejasen en ambos amigos un mismo sedimento. Si para Ribera fueron el arranque de una carrera profesional llena de logros intelectuales, para Menéu fueron unos años difíciles de los que debió restar un sedimento de frustración del que queda huella en unas anotaciones manuscritas de su puño y letra incorporadas a una lista de las publicaciones de Francisco Codera ${ }^{6}$. Dos alusiones hace a la ardua tarea de la Bibliotheca, cuya composición y corrección considera "trabajo en que perdí la flor de mi juventud, para ganar un mal comer, por abnegación y altruismo a favor de todos y de las letras arábigas, lo que empujó y favoreció la escuela de Codera y su biblioteca arábiga". En otro comentario, tras referirse a que Codera le cita en el prólogo del primer tomo de la Assila de Aben Pascual por su "pericia de cajista arábigo", dirá: "Ribera y yo apuramos la paciencia en esta obra".

Con apenas un año de edad de diferencia ${ }^{7}$, la cátedra de lengua árabe obtenida por Ribera en Zaragoza en 1887 y la marcha a Tánger de Menéu en la primavera de $1888^{8}$ separan ambas trayectorias y no

septiembre de 1899, Pons Boigues (que acababa de morir por entonces y de quien el primero preparaba una biografía), Ribera y Menéu se agruparon "alrededor de Chabás cuando éste publicaba el Archivo Valentino". Roque Chabás editó entre 1886 y 1893 la revista El Archivo de ciencias históricas en Denia, editándose siete volümenes.

${ }^{5}$ En expresión de Ribera en su artículo "El Ministro de Instrucción Pública en la cuestión de Marruecos", incluido en su obra miscelánea Disertaciones y opúsculos, tomo II, Madrid 1928, p. 438.

${ }^{6}$ Publicada a la muerte de Codera por el Marqués de San Juan de las Piedras Albas y enviada por éste a Menéu con dedicatoria. Fotocopia de esta bibliografía anotada me fue facilitada por el hijo de Pascual Menéu.

${ }^{7}$ Ribera había nacido en Carcagente (Valencia) en 1858 y Menéu en Bechí (Castellón) en 1857.

${ }^{8}$ En otra carta de Pedro Roca a Menéu de fecha 3 de agosto de 1900 , precisa aquél el momento de la marcha a Tánger "a montar la imprenta árabe de los 
volvemos, hasta esta correspondencia que ahora ve la luz, a encontrar lazos entre ambos amigos.

\section{Ribera investigador y publicista a través de la correspondencia}

Los años que cubren estas dieciséis cartas prolongan algunos de los de mayor intensidad en la vida de estudio de Ribera y constituyen, por sí mismos, algunos de los años más activos en sus investigaciones y proyectos. De todo ello queda puntual referencia en la correspondencia, que lógicamente aporta mucha más información del autor de las cartas que del receptor.

Empecemos por una de sus investigaciones claves, la que afectó al origen árabe de la institución del Justicia de Aragón y que dio lugar al volumen segundo de la Colección de Estudios Árabes, publicado en Zaragoza en 1897. Desde la primera de las cartas, de 17 de Junio de 1899 , llama la atención sobre la novedad de algunos de los resultados de la investigación y el tono que le había impreso: "tiré a que fuera de agradable lectura". Ya en la segunda carta, del 22 de septiembre de 1899 , se alegra del interés suscitado en Menéu por la publicación. "Me propuse dar el golpe definitivo y además que fuera la obra legible para el público general. Eso requería esfuerzo de orden y de lógica, al par que movimiento en la expresión", dirá. La voluntad de ser aceptado por el público corría parejo con una necesidad de convencer a los estudiosos: "Hasta ahora los más discretos ya se han convencido y los votos son favorables", expresará en la misma carta. Ciertas resistencias habrá sin embargo, como constan en la que escribe a Menéu de 20 de octubre del mismo año, en la que le dirá: "Los aragoneses, al fin, lo aceptarán todos en cuanto se mueran dos o tres recalcitrantes". Su seguridad y confianza en su descubrimiento no podrán ser más rotundas hasta asegurarle a su amigo: "Creo que el Justicia llevará turbante ya para siempre".

La actividad publicística de Ribera fue consustancial con esta voluntad de acercamiento al público de sus investigaciones. El empeño

Padres Franciscanos". Retorna a fines de 1889 a España, instalándose en Madrid desde principios de 1890 . 
difícil de la Bibliotheca, iniciado en Madrid y trasladado a Zaragoza era una actividad erudita para especialistas. De ahí que, para llegar al gran público, naciera la Colección de Estudios Árabes de la que se publicaron siete volúmenes entre 1897 y 1903. En un esfuerzo de divulgación aún mayor se creó también la Revista de Aragón, en colaboración con el historiador Eduardo Ibarra. Varias son las alusiones a la mencionada revista en la correspondencia con Menéu, empezando por la datada el 17 de Mayo de 1900 en la que le agradece formar parte de los doscientos suscriptores conseguidos en el primer año y le expresa la confianza de aumentar el número. Del interés que le merecía el trabajo en la misma dan testimonio los términos con que se refiere a ella en la carta de 23 de septiembre de 1903: "te dejará bizco por lo bonita, rica y elegante y útil", dirá a su amigo. De su labor incesante en la misma, dan idea los numerosos seudónimos con los que firma gran cantidad de colaboraciones: "En el número 7 va un artículo firmado por el Dr. Campiel q. es mio. Así como el del Dr. Cliché en el num ${ }^{\circ}$. 6. Con esto ya van seis o siete firmas las q. he usado en la Revista: $E l$ Maestro de Escuela, el Dr. Brayer, etc., etc." (carta de 25 de julio de $1900)^{9}$.

Menéu colaboraría en un número de esta revista de 1905 con su artículo "Influencia de la lengua española en el árabe de Marruecos", sin duda al que hace referencia Ribera en la carta de 5 de septiembre de 1904: "Yo no sé nada de la Revista, hace mucho tiempo. Si el original lo han mandado allá, supongo que no lo tirarán hasta que lo corrijas. Puedes estar descansado, que tomarán precauciones para que no salga con erratas. Y más de árabe". Son los momentos finales de la revista, coincidiendo con su traslado a Madrid en donde se seguiria editando con el nombre de Cultura Espanola.

${ }^{9}$ El Dr. Brayer, acróstico formado con la alteración de las letras del apellido Ribera, era la firma de una rúbrica irónica y crítica en la revista. "Me dedico a curandero de enfermedades sociales", dirá a propósito de dicho «Doctor» en el artículo recogido en Disertaciones y opúsculos, II, p. 717. Véase sobre esta actividad publicística de Ribera mi memoria de licenciatura "Aportaciones a un estudio de la estructura e ideología del arabismo en la España de la Restauración. El pensamiento de don Julián Ribera". Universidad de Granada, 1971. 


\section{Ribera y la cuestión de la enseñanza}

El traslado a Madrid de Ribera no fue la clásica escala en la carrera académica sino una circunstancia impuesta por una serie de hechos ajenos a la voluntad del arabista. Así lo expresa en carta a Menéu de 20 de octubre de 1899 haciendo referencia al proyecto de reforma de las Facultades de Letras emprendido por el Director General de Instrucción Pública, Hinojosa, que incluía la supresión de las Facultades de Letras de Zaragoza y Granada ${ }^{10}$ : "No sé lo que sucederá con estas reformas que se nos vienen encima. Codera tiene ganas de retirarse y yo no las tengo de ir a Maćrid. Me gustaría por estar en compañía de todos vosotros; pero, claro, mi presupuesto no alcanza para el lujo de vivir en Madrid, aunque ahr tenga que hacer la misma vida que aqui". Un año más tarde, en carta de 29 de noviembre de 1900, insistirá: "No sé si yo iré a Madrid. No tengo ilusiones; por lo único que me gustaría es por volver a renovar las impresiones de nuestra juventud con los mejores amigos que he tenido; pero aún no es seguro que vaya, me figuro".

Varios años pasarán aún hasta que se cumpla el proyecto, en el que mediará la renuncia por petición propia de Codera a su cátedra de Lengua Arabe de la Central, el traslado de Asín a Madrid y la promesa de creación de un Centro de Arabistas ${ }^{11}$.

El traslado a Madrid de Julián Ribera está pues inscrito dentro de sus preocupaciones por la enseñanza, tanto en su aspecto práctico como por su sentido social. Refiriéndose a dicho traslado dirá a Menéu en carta de 29 de noviembre de 1900 , sin duda en relación con algún comentario de éste en el que se proponía asistir a sus futuros cursos en la capital: "Si voy será para enseñar de manera distinta a la que tú has visto hasta ahora: de modo que si te prometes venir a oir mis luminosas

${ }^{10}$ Al que hará referencia Ribera en una entrevista al Diario de Avisos de Zaragoza el 14 de noviembre de 1899 y en un artículo en El Imparcial de 11-12 de septiembre de 1900, reproducidos en Disertaciones y Opúsculos, II, p. 483 y ss.

11 Sobre este centro, véase mi artículo "Julián Ribera y su 'Taller' de arabistas: una propuesta renovación", de Miscelánea de Estudios Árabes y Hebraicos, XXXIII, 1 (1984-85), pp. 111-128. 
explicaciones ya puedes renunciar a venir a mi clase. El ideal mio, es enseñar sin decir una palabra en discursos: no es más que a enseñar a trabajar en la forma que yo trabajo, es decir, a lo que yo sé. $Y$ hablando no se hace más que hablar". En estas pocas palabras se resumen gran cantidad de escritos de Ribera que le llevaron tanto a redactar un clásico sobre "La enseñanza entre los musulmanes españoles" ${ }^{12}$ como un libro sobre el sentido e historia de la educación, en el que expresó con profusión sus ideas acerca de la enseñanza: $L a$ superstición pedagógica ${ }^{13}$.

Hay en las cartas a Menéu continuas referencias a la redacción de esta obra. En la primera que ahora publicamos, le cuenta: "Yo estoy trabajando en acopiar materiales para una obra de más importancia que el Justicia y que supongo producirá más impresión, a algunos les parecerá escandalosa. Pero irá razonada y claveteada, hasta el punto de que yo creo que será inconmovible el resultado que he obtenido". Tras explicárle los vericuetos de su contundente razonamiento (considerar la organización de las Universidades como una de las más funestas para el progreso científico), concluirá a propósito del estado contemporáneo de las Universidades: "Esto al punto parece terrible. Lo horroroso es lo q. pasa hoy".

En la fechada el 22 de septiembre de 1899 vuelve a contar que está escribiendo un libro sobre las Universidades para explicar "racionalmente de donde derivan los vicios de la enseñanza universitaria. Estudiando sus orígenes se da uno cuenta de todo, de] hecho, y de todas las consecuencias. Esa es la novedad q. puedo traer; aparte de las revelaciones q. puedo hacer, siendo como soy hombre franco y sincero (según creo) que no me arredro para decir todo lo $\mathrm{q}$. sea menester. Aún los de fuera de la Universidad me parece q. se escandalizarán. Lo que digan los de dentro, me tiene sin cuidado y hasta estaría dispuesto a dejar la cátedra y retirarme, si fuera preciso, para decir la verdad". Un mes más tarde (20 de octubre) precisará aún más

${ }^{12}$ Materia de su discurso de apertura del curso 1893-94 en la Universidad de Zaragoza, publicado en esta cjudad en 1893 y reproducido en Disertaciones y Opúsculos, I, pp. 228-360.

${ }^{13}$ Dos volúmenes en octavo de 236 y 262 páginas, publicados en la Imprenta Maestre en Madrid en 1910. 
la envergadura del proyecto: "Lo de la enseñanza va para largo. Creo que aún seguiré reuniendo materiales durante este curso y ordenando la materia. La redacción costará un año o dos por lo menos; la cosa será un poco más larga que lo del Justicia. Supongo que dos o tres tomitos, si no se abrevia al tiempo de redactar".

Un año más tarde (29 de noviembre de 1900), aludirá de nuevo a esta obra en referencia a la concepción de los estudios de Menéu y su papel en la vida: "Cuando yo publique una obra acerca de enseñanza te se [sic] quitarán los escrúpulos que ahora tienes. Allí probaré que la instrucción mejor no es la que tú pretendes encontrar". Unos párrafos más adelante calcularía en un año el inicio de una publicación que se demoraría aún una década.

La figura de Codera aparece en la correspondencia como una referencia, bien a propósito del homenaje que los discípulos le ofrecían o del Centro de Arabistas que se iba a crear en Madrid. El libro de homenaje, preparado como dice en carta de 23 de enero de 1903 por él, Saavedra, Hinojosa, Menéndez Pelayo "y los de la hermandad", aparecería en 1904. En dicha carta le informa que los colaboradores en el mismo en activo se les exige "diez duros y articulo por barba". Y exime a Menéu, "por estar de reemplazo, de ofrecer artículo". Alusión sin duda a una situación de excepción vivida por Menéu que debió marcarle durante esos años ${ }^{14}$.

${ }^{14}$ Son varias las referencias a un pleito (la separación de su primera mujer) en los comentarios manuscritos a la bibliografía citada de Codera. A propósito de la publicación del homenaje a Codera por sus discípulos, escribirá al margen: "Menos yo, por estar engolfado en el pleito con mi adorado tormento". En relación con el viaje de Codera a Túnez y Argelia para adquirir códices y monedas anotará: "En 1905 ? tuvo con Asín otro viaje a Argel [se refiere a la asistencia al Congreso Orientalista celebrado en dicho año en esa capital; se conserva una carta de Codera a Menéu fechada el 25 de mayo de 1905, a su retorno de Argel, Orán y Tremecén]; al que me invitó, y me negué en venganza a Ribera y Asín, porque anulados [?] de mi pleito, no me nombraron en la lista de profesores del Instituto Codera que decretó crear Maura-Dominguez Pascual". A pie de la página añade: "Este Instituto fracasó por intrigas del badulaque Sanchez-Moguel, y por la Justicia divina, que no podía ver mi preterición entre los profesores del Instituto Codera". En la carta de Ribera a Menéu de 15 de septiembre de 1904 hace referencia a "una lista de personas aficionadas" propuesta al Ministerio para el citado Centro: "No tuve olvidos voluntarios", 


\section{La cara humana del arabismo a través de las cartas}

Comentaba al principio de este artículo el interés del género epistolar para conocer el trasfondo humano de los correspondientes. Estas cartas que a continuación se transcriben informan de la evolución de los hijos de Ribera y sus estudios, aficiones y disposiciones, en un tono que revela una relación entre ambos correspondientes claramente familiar como indica la consideración de Menéu como "el tío Pascual". Las cartas dan también noticia de una actividad de Ribera como excursionista veraniego en compañfa de Asín y otros amigos para escapar de la rutina del trabajo y estudio. "Esos días -dirá en carta de 25 de julio de 1900- los destino yo a pasar el tiempo en el campo, tendido bajo la sombra de los árboles y sin ganas de discursos ni preocupaciones". En la siguiente -del día 31-precisará su programa para una de sus "correrías": "Nada de empaque y seriedad; nada de tratar de asuntos de libros y haciendo esfuerzos de inteligencia; eso está prohibido porque deseamos descansar de tareas intelectuales por medio del reposo de la cabeza y la actividad de todo el cuerpo (...) Uno de los placeres a que mayor tiempo y más actividad dedicaremos será estar tendidos patas arriba en la verde hierba fumando algunos cigarros habanos. Yo no los fumo en todo el año; pero en ese tiempo desearía tener los mejores del universo para chupar en el campo, donde nadie me vea, a mis solas". Excursionismo que será ingrediente básico en la cultura de ciertos intelectuales de la época puesto de moda por institucionistas como Giner de los Ríos.

Las cartas finales hablan del Ribera propietario levantino, de la relación con su hermano, de los preparativos del traslado a Madrid y de las disposiciones en relación con la venta de propiedades así como de la necesidad de un préstamo finalmente facilitado por Menéu.

diría. En las dos notas de Ribera y su hijo (cartas 16 y 17 de la transcripción) se hace referencia a la conclusión de dicho "pleito". 


\section{Menéu a través de las cartas de Ribera}

Es Pascual Menéu un arabista poco conocido, sin duda debido a que su labor ha sido menos pública que la de otros elementos de la escuela de Codera. Muestra sin embargo esta correspondencia que su papel como intermediario fue muy apreciado por los "padres" de dicha escuela. La conexión con Tánger y Lerchundi, la búsqueda de libros por Marruecos, la actividad tipográfica, son algunas de las muestras de este papel más velado que desempeño en los años de fin del pasado siglo.

Menéu aparece en estas cartas reflejado en la retina de otros: para Asín, que acababa de conocerlo durante una excursión en el verano de 1900 , es "el hombre más campechano que ha visto", según referirá Ribera; para éste aparece como hombre de vida regalada y sedentaria que atraviesa una fase de insomnios y preocupaciones. Aparece entonces en las cartas la faceta de Ribera como el Dr Brayer que diagnostica al amigo: "es el reverso nuestra vida". Y le recomienda: "una vida activa, sin preocupaciones graves; aunque sea en trabajos caseros etc., podrían activar el movimiento q. es necesario para la salud".

Aunque en otra carta le insistirá: "La medicina es no acordarte de los libros" (29-11-1900), y en momento de preocupaciones le indicará que "en lo de trabajos literarios, no te empeñes en cosas grandes, sino con ánimo de hacerlos despacio y con tiempo, para que sea una distracción útil y no una grave preocupación" (20-10-1899), más adelante, en otra carta de 31-1-1903, tratará de animarlo a través del trabajo, proponiéndole que participase en el homenaje a Codera con "algún cuentecito inédito, aljamiado, de los q. pueda haber en la Biblioteca Nacional".

Las dos notas finales de Julián Ribera y su hijo no están fechadas pero deben estar escritas hacia fines de 1904 o 1905 por las alusiones a la conclusión del pleito antes referido. Se nos pierde aquí el rastro de la amistad entre Ribera y Menéu ${ }^{15}$, que años más tarde serf́a catedrático de Hebreo en Salamanca y Granada, donde ejerció a su vez

15 ¿Empañada tal vez por la cuestión de su "preterición" del Centro de Arabistas, referido en nota 14?. No tenemos más datos para deducirlo. 
la enseñanza de la lengua árabe y que fallecería a los 77 años en Bechí el 29 de julio de 1934.

$* * *$

\section{TRANSCRIPCIÓN DE LAS CARTAS}

Mi querido amigo Pascual:

Me alegré mucho de recibir carta tuya y fue leída por todos los chicos que se acuerdan de su tío Pascual, del que guardan buena memoria.

Efectivamente estamos en pie de marcha para Carcagente. Esta semana, regularmente el dia de $\mathrm{Sn}$. Juan, saldremos de aquí. Elijo ese día porque confío encontrar los coches más vacíos; pues saliendo de Madrid el expreso de Barcelona en donde montamos, no es fácil, todos los días, encontrar un departamento vacío para la gente que llevo. Y no quiero verme en la necesidad de partirnos en dos departamentos, siendo todo chiquillos $[\ldots \ldots \ldots . . .]^{16}$ años y encontramos el tren casi vacío, y nos acomodamos todos perfectamente.

Asín fue a Oñate, en concepto de arabista para examinar. Si al año que viene vuelvo a examinar, ya te avisaré y bien sea en Mayo, bien en Agosto, nos veremos por esas tierras, si como espero y me dices, estáis por ahí.

Ya me dirás algo de lo que te parezca mi Justicia. Confío en que lo leerás sin cansarte mucho, porque tiré a que fuera de agradable lectura. Sobre todo lo de la imitación que es teoría nueva.

Si encuentras muy pesada la música la dejas; siempre vale más oir que tocar, y se aprende lo mismo oyendo que tocando, es decir, lo mismo se adquiere el

${ }^{16}$ [Nota del transcriptor] $\mathrm{La}$ transcripción de las cartas se ha hecho a partir de fotocopias, como se ha dicho, facilitadas por don Pascual Menéu y Monleón, hijo del receptor de las mismas. Hay algunos renglones cortados y alguna palabra ilegible que no han podido ser cotejadas con el original. Puesto al habla con aquél, me confirmó la dificultad de encontrar los originales, por lo que he debido marcar con corchetes y punteado lo imposible de reconstruir. 
gusto. Quizá mejor oyendo, porque siempre se oye a otros mejores músicos que lo que pueda ser uno.

No comas mucho, pasea y muévete, y no te preocupen intensamente muchas cosas; así te se [sic] pasará eso de la cabeza.

Entretente en algo que sea distraido en casa.

Todos los chicos han salido bien. Julián toca el piano, al que tiene mucha afición. En dos años que va al Conservatorio de aquí ya toca mucho mejor que yo. Este año conmemorarán el grado mis dos más pequeños. Y la niña sabe leer, marca ropa, y se ha hecho chambras y camisas. Es viva y trabajadora.

Mi hijo segundo que estuvo malo el verano pasado, se ha puesto bueno en Valencia, donde pasó el invierno.

Trinidad me encarga q. salude especialmente a María, a la que darás cariñosos recuerdos de todos, haciéndolos extensivos a tu sobrina.

Yo estoy trabajando en acopiar materiales para una obra de más importancia que el Justicia, y que supongo producirá más impresión, a algunos les parecerá escandalosa. Pero irá razonada y claveteada, hasta el punto de que yo creo que será inconmovoble el resultado que he obtenido. Refiérome al origen de las Universidades. Considera qué caminos tomaré para llegar al resultado siguiente: Una de las formas de organizar la instrucción más funestas para el progreso científico, es la organización de las Universidades. Allí saldrán todos los defectos de Catedráticos, alumnos, falta de disciplina, de donde viene \&. Resolución final: se cierren la mayor parte de las Universidades dejando libre el ejercicio de todos los profesores científicos, aboliendo títulos \& \& \&.

Esto al pronto parece terrible. Lo horroroso es lo que pasa hoy.

Esto me hace trabajar mucho. Necesito descansar tres meses y en Carcagente no leeré ni un periódico. Allí me tendrás durante el verano $[\ldots . . . . . .$.$] tu amigo$ del alma

\section{Querido amigo Pascual:}

Recibí tu apreciable del 3 y escribí a Valencia recomendando a D. Julián Doñate y Franch, pues en aquel entonces ya había yo vuelto a Zaragoza de las vacaciones del verano. El dia dos de setiembre llegamos a aquí. Confío en que pueda valer la recomendación de las personas a quienes la he encargado. 
Veo por la tuya que aún sigues tocando teclas y entreteniéndote con la música. No quieras correr mucho; paulatinamente te será más fácil mantener la afición; que el tocar bien no se logra con intensidad de estudio, sino con la constancia en ir tocando y practicando.

Ya veo que eres un convencido antes de leer mi futuro libro acerca de las Uni [ .] de un modo instintivo, como la mayor parte, sino explicándome racionalmente de donde derivan los vicios de la enseñanza universitaria. Estudiando sus origenes se da uno cuenta de todo, del hecho, y de todas las consecuencias. Esa es la novedad q. puedo traer; aparte de las revelaciones q. puedo hacer, siendo como soy hombre franco y sincero (según creo) que no me arredro para decir todo lo q. sea menester. Aún los de fuera de la Universidad me parece q. se escandalizarán. Lo que digan los de dentro, me tiene sin cuidado y hasta estaría dispuesto a dejar la cátedra y retirarme, si fuera preciso, para decir la verdad. Con que ya puedes suponer si tendré vanos miramientos sociales. Para tenerlos, no tra[.......... dando vueltas a la noria.

Me alegro de que te haya divertido lo del Justicia. Me propuse dar el golpe definitivo y además que fuera la obra legible para el público general. Eso requería un esfuerzo de orden y de lógica, al par que movimiento en la expresión. No sé si por completo lo he conseguido. Hasta ahora los más discretos ya se han convencido y los votos son favorables. Creo que el Justicia llevará turbante ya para siempre.

Del pobre Pons ya no recibirás cosa que te moleste. El dia seis de este mes pasó a mejor vida, víctima de un antrax que le llevó al sepulcro en Carcagente. En su testamento lega la mayor parte de su fortuna (que no era exigua para un empleado) consistente en láminas del Banco Hipotecário, por valor de nueve o diez mil duros, para pagar la carrera a chicos pobres de Carcagente. Hizo una muerte edificante, dejando en todos buenos recuerdos, que harán olvidar las susceptibilidades de su genio en vida. Dios le tenga en su gloria.

Me vas chocando mucho lo que me dices de tus insomnios y tus envidias de los que duermen. Eso no es nada, quizás contribuyas, con tu clase de vida, a que eso suceda y se prolongue. Vida un poco más distraida y activa, un poco menos regalo de mesa, y un poco más de calma interior, serán los remedios seguros para eso. Yo me atreveria a encontrar la causa y la medicina, si tuviéramos algunas conversaciones tan francas como las teníamos cuando éramos estudiantes.

Yo estoy un poco delicado del estómago, pero cesa en cuanto dejo de trabajar algunos días, $y$ con distraerme y comer bien. Es el reverso nuestra vida.

Saluda cariñosamente a María, re[.....................] 
Querido amigo Meneu:

Recibi tu apreciable del $17 \mathrm{y}$ he repetido las recomendaciones a mi hermano Vicente que está en Valencia y mi cuñado el diputado, por si se les olvidó que lo hagan y si lo hicieron que la repitan.

Lo de Raimundo Lulio lo ha aceptado Menéndez Pelayo y le parece concluyente el argumento. A él, sin embargo, le hacen pero razones que yo creía no tan importantes. En fin, si cada uno pondera el valor de los argumentos de distinto modo, el resultado es el mismo, es decir, que el intento de mi trabajo se ha cumplido y es aceptado. Lo mismo que lo del Justicia. Los aragoneses, al fin, lo aceptarán todos en cuanto se mueran dos o tres recalcitrantes.

Me alegro que te vayas aliviando de tu indisposición. Algo de exceso de vida sedentaria (el coche no es bastante ejercicio para tí), algo de exceso de comida, que produce grasas y linfa, podrían ocasionar los insomnios etc. etc. Una vida activa, sin preocupaciones graves; aunque sea en trabajos caseros etc., podrían activar el movimiento q. es necesario para la salud. No encerrarse en teatros, con el calor, gas, etc., sino de vez en cuando etc. etc. Y sobre todo no atracarte en comidas-cenas, entrada ya la noche; y ver de vez en cuando la luz y el fresco de la mañana.

Si tuvieras seis hijos como yo, te tenderías en la cama con ganas de dormir. Yo tomo siesta y duermo por la noche ambas cosas las necesito. Porque después de comer a medio dia (pues en esto soy español) necesito una horita de descanso $[\ldots \ldots \ldots \ldots \ldots . . .$.

En lo de trabajos literarios, no te empeñes en cosas grandes, sino con ánimo de hacerlos despacio y con tiempo, para que sea una distracción útil y no una grave preocupación. Haz lo que creas que puedas hacer bien, con utilidad agena [sic] y honra propia.

Lo de la enseñanza va para largo. Creo que aún seguiré reuniendo materiales durante este curso y ordenando la materia. La redacción costará un año o dos por lo menos; la cosa será un poco más larga que lo del Justicia. Supongo que dos o tres tomitos, si no se abrevia al tiempo de redactar.

Toma pocas medicinas; me parece bien q. las pocas que tomes te las prepare María, a quien saludarás cariñosamente de parte de todos nosotros. Le deseamos, lo mismo que a tí, salud y felicidades.

No sé lo que sucederá con estas reformas que se nos vienen encima. Codera tiene ganas de retirarse y yo no las tengo de ir a Madrid. Me gustaría por estar en compañía de todos vosotros; pero, claro, mi presupuesto no alcanza para el lujo de vivir en Madrid, aunque ahí tenga que hacer la misma vida que aquí. 
Tengo un hijo aprendiendo el oficio de impresor, otro el de litógrafo. Los otros tres estudiantes. El mayor, letras. Los otros dos ya veremos cuando acaben el grado de Bachiller, cuyos estudios hacen ahora.

Trinidad me encarga saludos especiales para tu señora y sobrina.

$\mathrm{Y}$ manda de tu afmo. amigo que te quiere

Juliân

Zaragoza 20 Octubre 99.

Querido amigo Pascual:

Dispénsame. Hace dias que pensaba escribirte felicitándote en el dia de tu santo y ha llegado éste sin aprovechar la víspera para que la carta llegue a su debido tiempo. De todos modos creo que por eso la felicitación no será menos cariñosa y bien recibida. Muchos años, pues. La felicitación hágase extensiva a tu simpática esposa, a quien deseo también salud y felicidades.

Esta temporada ha sido bastante mala para mí. Trinidad tuvo un aborto el dia de Jueves Santo. Como no llegaba a dos meses que estaba embarazada y ella no lo sabía, ni se había dado cuenta, ni lo había sospechado siquiera, no atinó en lo que le pasaba y creyó que era un trastrueque de la menstruación. El caso fue que en vez de meterse en cama, continuó en los quehaceres ordinarios; sobrevino una hemorragia tremenda y no se cuidó hasta que la infeliz estaba medio desangrada. Cuando vino el médico la encontró medio muerta. Y entre medicinas y una cosa y otra, esta es la hora en que comienza a convalecer. He pasado una trifulca larga y pesada. Ocurrió el caso cuando nos hallamos sin criada ni nada. Considera mi situación con tanto chico y tanta familia. En fin, ya pasó la tronada y parece que se va reponiendo un poco y pasando el peligro.

Como me había comprometido a dar unas conferencias, tuve que trabajar también por ese lado.

Habrás recibido un folleto que las contiene. ¿Qué te parece de las cosas que digo? Supongo que en muchas cosas pensarás como yo.

Toda mi gente ahora está ocupada con la proximidad de los exámenes.

Yo voy de comisión a Oñate a examinar el lunes de la semana que viene, si no mienten las crónicas. $Y$ tendré que repetir el viaje en el mes de agosto. A ver si tú estás también este año por Vascongadas y tenemos ocasión de vernos. 
Toda mi familia se asocia a la felicitación, encargándome que saludes cariñosamente a María y a tu sobrinita.

$Y$ te abraza tu afmo. amigo que te quiere

Juliản Ribera

Zaragoza 17 Mayo 1900

Te agradezco también el que seas suscritor a la Revista de Aragón. En la Revista tendré más lectores que en la Colección de Estudios Árabes. El ler. año llegaremos cerca del número 200 de suscritores. $\mathrm{Al}$ año que viene aumentarán.

Querido amigo:

He recibido tu apreciable que he leido con mucho placer; como siempre que recibo carta tuya.

Según tu deseo te envío el número 6 de la Revista, correspondiente al mes de Junio. Como hice yo las fajas del mes de Julio, me acordé, al tiempo de hacer la tuya, que debía mandártela a S. Sebastián. En el número 7 va un artículo firmado por el Dr. Campiel q. es mio. Así como el del Dr. Cliché en el num ${ }^{\circ}$. 6. Con esto ya van seis o siete firmas las q. he usado en la Revista: El Maestro de Escuela, el Dr. Brayer, etc. etc.

Cumpliré mi promesa de visitaros, a tu señora y a tí, en S. Sebastián este verano; pero será eso a fines de agosto.

De aquí saldremos de correría el dia 15 o 16 de Agosto, en primer lugar a Pamplona; ahí cogeremos el automóvil que nos llevará al Baztán, al pueblo de Elizondo. Ese será cuartel general; de ahí a Roncesvalles y otros lugares del contorno. De allí a S. Juan de Luz. No sé si daremos un vistazo por Biarritz y de ahí a S. Sebastián. De ese punto saldré para Oñate y de Oñate a casa a principios de Setiembre. Todo en 15 dias. De modo que en S. Sebastián estaremos dos o tres dias. Y si no fuera por verte a ti y a tu señora, no estaría ahí más de un dia, porque a mi el ruido de la gente me marea en esas circunstancias. Esos dias los destino yo a pasar el tiempo en el campo, tendido bajo la sombra de los árboles y sin ganas de discursos ni preocupaciones; bastantes tengo yo en mi casa y quehaceres.

Esta excursión la hago en compañía de Asín y otro clérigo, y no sé si algún otro se agregará. A mí no me sabe mal que me obsequies pagándome la fonda; 
pero como voy en compañía de otros, no es menester que demuestres tu buena voluntad de esa manera. Si acaso te avisaré para que nos busques una casa de huéspedes dondé podamos estar sin lujo, ni pobreza; pero a cargo de nuestros bolsillos.

Si quieres obșequiarme te permitiré que me convides una tarde o una mañana de excursión a pie o carruaje por los pueblos de alrededor de S. Sebastián y Pax Christi. Y eso por tener el gusto de echar una cana al aire y charlar un rato de nuestras antiguas gestas.

También juzgué yo del mismo modo el librejo aquel impreso en Tánger. Es un mamotreto de un desdichado q. no sabe lo q. pesca; pero habrá dado quéhacer a la imprenta de los Padres.

Mis chicos van siguiendo. Julián el mayor ha estudiado en 1er. año de la carrera de Letras; el $2^{\circ}$ (Vicente) sigue en la imprenta; el $3^{\circ}$ (Carlos) con su penúlt ${ }^{\circ}$ año del grado de Bachiller; el $4^{\circ}$ (Agustín) tan campechano en la litografía; el $5^{\circ}$ (Pedro) ha estudiado el primer año del grado; y la niña (Trinidad) va siguiendo. Este invierno ha ido poco al colegio, pues su madre ha estado enferma algunos meses (de un aborto) y ella estuvo algo delicaducha: Primero es tener salud y fuerza; luego lo demás. No estoy descontento de ella: es trabajadorcilla y lista; pero se le esperará entretenimiento en mi casa, donde todo son chicos.

Ahora estoy acabando el num ${ }^{\circ} .8$ de la Revista; y en seguida el 9, para marchar descansado a la excursión, sin tener que pensar el el trabajo de la vuelta.

Saluda de parte de Trinidad, cariñosamente, a Maria (y de los chicos) y sabeis que os quiere de veras vuestro afmo. amigo

Julián Ribera

Zaragoza 25 Julio 900.

6

Zaragoza 31 Julio 900

Querido amigo Pascual:

Todos los expedicionarios están muy contentos de la compañía que nos prometes en la expedición por el Baztán. Ya te avisaré por telégrafo o como sea para que salgas a Pamplona donde nos podemos reunir. 
Las prevenciones para ese viaje son pocas: una maletilla de poco peso con una o dos mudadas de ropa interior; dos trajes malos, el de ponerse y el de reserva; dos pares de alpargatas para las excursiones a pie y unas botas para cuando se está en poblado; si puedes procurarte unos buenos gemelos o catalejo o anteojo de larga vista, será muy útil, para cuando subamos a las alturas de los montes (según me dicen desde los montes de Roncesvalles se divisa extensísimo y hermoso panorama); un abrigo de verano para los ratos de frío; un paraguas para las lluvias; y por fin, muchas ganas de pasar en el campo, y fuera de la gente $y$ el mundo, ocho dias.

Se han de permitir todas las expansiones del buen humor, aún en formas que la sociedad no suele admitir, con tal que no sean inconveniencias en daño de los compañeros. Nada de empaque y seriedad; nada de tratar de asuntos de libros y haciendo esfuerzos de inteligencia; eso está prohibido porque deseamos descansar de tareas intelectuales por medio del reposo de la cabeza y la actividad de todo el cuerpo. Los paseos más largos podrán ser de cuatro a cinco horas, cuando la necesidad lo reclame; dos o tres horas término medio diario, cuando no se vaya en coche o ferro-carril; en fondas u hospederías cuyo importe diario no pase de cinco pesetas porque ese es el máximum que permite el caudal de la compañía.

Sabidas estas prevenciones, anímate. Uno de los placeres a que mayor tiempo y más actividad dedicaremos será estar tendidos patas arriba en la verde hierba fumando algunos cigarros habanos. Yo no los fumo en todo el año; pero en ese tiempo desearía tener los mejores del Universo para chupar en el campo, donde nadie me vea, a mis solas.

Estos dias haz ejercicio, no sea que por entonces te parezca pesado el andar. Si quieres algo de esta tierra, avisa.

Me alegro que vengas, no sólo por verte, sino porque eso supone que tu cara mitad se encuentra mejor que en otras ocasiones.

Asin y los compañeros te saludan de antemano y se prometen ser para contigo como amigos de toda la vida, pues te conocen por mis informes, como antiguo conocido.

Conque basta, porque estoy cansado de escribir. Acabo de mandar un artículo para El Imparcial de 21 cuartilla que tú leerás, si es q. lo compras el miércoles o el jueves por la noche o más tarde, si les conviene; o nunca si no me lo aceptan (aunque si lo he mandado es por habérmelo pedido, pues demasiados quehaceres tengo para meterme en dibujos por mi gusto).

Un saludo afmo. para tu señora y un abrazo para tí de tu amigo 
Querido amigo Pascual:

Después de tres dias de Oñate y una noche en Pamplona llegué, sin novedad, a casa, encontrando a chicos y chacos con buena salud y alegría de verme. Esta se aumentó al destapar la maleta donde sabían los chicos que se encerraban tus regalitos. Todo fue celebrado y agradecido; los imperdibles de Lurdes, los manguillos y navajitas de S. Sebastián \& \&. A coro se agradeció el recuerdo de tu querida esposa y tuyo. Todo el mundo se guardó el regalo. Mi mujer y la chica, se pusieron enseguida el imperdible. Ya ves si se utiliza.

Yo poniendo ya en orden los papeles para comenzar la tarea. Me he pesado y resulta que he ganado tres kilos en la expedición. ¿Te pesaste tú también? Tú debiste perder con [..............] mente la de Alduides dos o tres kilos, pues si bien es verdad que cumplías en la mesa como buen excursionista, también lo es q. hay q. descontar los efectos del ricino de Roncesvalles.

Yo no me puedo quitar de la memoria el recuerdo de la expedición de $\mathrm{S}$. Sebastián: la subida por aquellas cuestas lloviendo a mares, la casita del guarda, la mojadura del pinar y la bajada tan cómoda y segura que hicimos por aquellos caminos que parecian barranqueras.

Sobre todo recordando el cambio de decoración que sufrimos al vernos en seco comiendo aquella langosta y aquel cangrejo de Pasajes. ¿Qué bien se estaba en aquella terraza junto al mar! ¡Lástima que se unan a ese recuerdo las consecuencias sufridas por tu esposa, con el viento y la lluvia de aquel dia!

Yo tendré recuerdos para mucho tiempo. Es una excitación para que venga el deseo de repetir la expedición por los montes.

Con mucho gusto seguiría la carta; pero tengo otras muchas cosas pendientes y dejo ésta con disgusto.

$\mathrm{Si}$ ves a los curicas, tantas cosas. Estuve ayer en casa Asín y me dijeron haber recibido carta por la q. se deduce q. no piensan volver tan pronto como decían. Que estiren lo q. puedan.

Trinidad y los chicos saludan afectuosamente a tu señora (c.p.b.). Recuerdos a Remigia y a Roblesito.

$Y$ te abraza tu afmo. amigo

Julián

Zaragoza, 3 Setiembre 900 
Dime: ¿Vive en tu casa el Sr. Sánchez y Moguel? ${ }^{17}$

Zaragoza 29 Nbre 1900

Querido amigo Pascual: Con mucho gusto leimos tu carta, pues hemos tenido con ella noticias vuestras, que nos faltaban desde la salida vuestra a París. Me alegro del feliz viaje etcétera y demás (como decía uno de mi pueblo).

En cumplimiento de tu encargo fui a preguntar a los PP Jesuitas donde vivia tu recomendadalimeña $D^{a}$ María Rosa Sisson; pero al llegar a la fonda donde me habían dicho que se hospedaba, me dijeron que había salido para Barcelona. Es decir, la cardelina había volado de la jaula. Me supo mal no haber podido presentarle mis respetos, pues además del gusto de verla, hubiera recibido noticias vuestras que ella me hubiera dado.

Veo por la tuya que estás bueno; pero q. te sabe mal tener salud. Así no es extraño que te pongas malo: si ves que la vida que llevas te prueba, qué demonio te metes a variarla? Regularmente si te pones a estudiar lo que nada te importa, tomarás después medicinas para curarte, cuando la medicina es no acordarte de los libros. Cuando yo publique una obra acerca de enseñanza te se quitarán los escrúpulos que ahora tienes. Allí probaré que la instrucción mejor no es la que tú pretendes encontrar. Y que huyes precisamente de la única que debes buscar.

No sé si yo iré a Madrid. No tengo ilusiones; por lo único que me gustaría es por volver a renovar las impresiones de nuestra juventud con los mejores amigos que he tenido; pero aún no es seguro que vaya, me figuro.

Si voy será para enseñar de manera distinta a la que tú has visto hasta ahora: de modo que si te prometes venir a oir mis luminosas explicaciones ya puedes renunciar a venir a mi clase. El ideal mio, es enseñar sin decir una palabra en discursos: no es más que a enseñar a trabajar en la forma que yo trabajo, es decir, a lo que yo sé. Y hablando no se hace más que hablar.

Asín y Gómez me encargan te salude cariñosamente. Se acuerdan mucho y con gran placer de los dias $q$. pasaron en compañia tuya. $Y$ te tienen por el hombre más campechano que han visto. Eso ya se lo decía yo a ellos. Y han confirmado mi juicio.

${ }^{17}$ [Nota del transcriptor: Se debe tratar de Antonio Sánchez Moguel, literato e historiador (1838-1913), catedrático de Literatura general española primero en Zaragoza (1878) y más tarde en la Central, que fue consejero de Instrucción pública durante muchos años.] 
Me encargan ambos que salude de parte de ellos a tu señora a la que recuerdan con cariño y respeto.

Si yo fuera a Madrid y Asín (por consecuencia) tuviera que acompañarme, ya decidiríamos acerca de las proposiciones que le hacen de desempeñar el oficio de capellán de casa grande. El agradece mucho el buen propósito; y si llega el caso, yo trataría de ponerme de acuerdo contigo para que le digas dónde $\& \& \&$.

Yo sigo dándole a mi tema. Y si tengo paz y me dejan aquí, creo que no pasará un año sin que veas el primer tomo de los dos o tres que son precisos para desarrollar todo el estudio.

A mi lado tengo a mi mujer que lleva en el cuello el imperdible que le regaló tu señora como recuerdo de Lourdes. Me encarga que os salude afectuosamente. Toda la patrulla me dice que dé muchos recuerdos al tío Pascual.

De mi parte los respetos a tu señora (a quien estoy muy agradecido por las atenciones q. nos dispensó en San Sebastián), recuerdos a Remigia y al pequeño Robles y un abrazo para tí de tu afmo. amigo

$\underline{\text { Julián }}$

Querido amigo Pascual:

Hace un siglo que no sé de tí; no me acuerdo quien me dijo que te había visto en Valencia (creo que el P. Vicent a quien regalaste un libro de mucho valor, según me contó). Y me parece que el P. Francisco, al pasar por acá, me dijo que estabas por San Sebastián, o creía al menos que habías de estar. A San Sebastián, pues, te escribo en la confianza de que llegará ésta a tus manos. Y para decirte que este año pensamos repetir la excursión y que nos harías un singularísimo favior si te agregaras a ella.

El plan es el siguiente: salir de aquí para Pamplona; de ahí a Aoiz; de donde a pie, en mulo o en diligencia pasaremos al Roncal, precioso valle; de éste a otro no menos agradable que se llama Ansó; de allí al valle de Hecho; y de Hecho a Canfranc; siempre por lo más abrupto del Pirineo Navarro y Aragonés.

En Canfranc quizá se divida la expedición: los curitas se irán a Francia por Olorón y Pau, Lourdes, Bayona y San Sebastián, donde pasarán algunos días; y yo me volveré por Jaca a Zaragoza, sin acompañarles en sus recreos por sitios muy poblados.

Esto será comenzando la expedición allá por el 10 de Agosto.

Antes voy. yo a un viajecito. El dia 22 o 23 de este mes hago un viaje circular; pasando por Madrid iré a Córdoba, donde me esperará un americano a 
quien voy a ver (es el traductor al inglés de una obra mía). De Córdoba iré a Valencia, mi pueblo \&. arreglaré mis cosas, veré a la familia y allá el 4 de Agosto de vuelta a Zaragoza. Al pasar por Monzón (via de Lérida) entraré en el pueblo por ver el Monasterio de Xiquena, acompañado de un amigo q. me espera en Monzón. Y allá por el siete u ocho entraré en mi casa de Zaragoza dispuesto a salir para la excursión pirinaica (sic) de q. antes he hablado.

Avisa ahora tus intenciones para q. cuando llegue el caso te podamos avisar la salida \&. La expedición pirinaica [sic] podrá durar ocho o diez dias. Eso te lo consentiría tu muger [sicl, q. es muy buena.

Salúdala en mi nombre y en el de Trinidad y los chicos. Le deseamos salud y felicidades. A Remigia también, supongo q. estará por ahí y seguirá tocando el piano.

Ya sabes que te quiere tu afmo. amigo

Julián

Zaragoza 10 Julio 1901

Te verifico el viaje yendo los cuatro de Pamplona a Roncal y de este por Iraba a Ansó y por Hecho [sigue en la vuelta, en la cabecera de la carta] Hoza, La Mina, Guarruida, Aguas Muertas, Escalé, La Jundería, Canfranc volviendo a Oloron y Pau y S. Sebastián en 20 Agosto 1901.

\section{Querido amigo Pascual:}

Estando en Carcagente recibieron en casa tu carta de pésame en la que se translucía las penas y dolores que has pasado durante algunos dias con motivo de grave enfermedad de tu señora. Como tu carta no lleva lugar de fecha, supongo q. estás en Madrid y allí dirijo ésta (Habiendo hablado con Codera, ahí debes estar.)

Sentimos mucho la enfermedad de María y nos alegramos de que se haya disipado la tronada restableciéndose y volviéndote la paz y la calma.

Nosotros hemos pasado un mes de Setiembre de perros. Mi mujer tuvo que parcharse por la enfermedad de su madre y me quedé sólo en casa. Luego vino y fue peor, pues se metió en cama y estuvo algunos dias. $Y$ al levantarse estaba tan débil q. no se reponía fácilmente, a puro cuidado y tiempo se va fortaleciendo. 
Me acuerdo mucho de las caminatas de este verano y todo lo q. con motivo de ellas charlábamos. Había en todo ello mucha filosofía, especialmente en aquella visita al cementerio del Roncal donde tiene el hermoso monumento a Gayarre, aquel caminito, los cantos de la era, la sombra de la escuela que él fundó \& \&. ¿Te acuerdas?

Cuidáos mucho tú y tu señora para que la vejez sea dichosa. Ya nos van saliendo los cabellos blancos.

Asín y Gómez me encargan un saludo y un recuerdo afectuoso.

$Y$ con la esperanza de recibir buenas noticias vuestras se despide tu amigo q. te quiere

$\underline{\text { Julián Ribera }}$

Zaragoza 18 Octe. 901.

11

Amigo Meneu:

Estoy de quehacer hasta la coronilla. Con enfermos en casa (hace tres meses Trinidad está en cama; comienza a levantarse estos dias), con la Revista de Aragón (que te dejará bizco por lo bonita, rica y elegante y útil), con la campaña q. voy a emprender en El Imparcial (sobre Marruecos) y con el trabajo que he tenido q. enviar a Madrid para el libro de homenaje a D. Francisco (q. le hacemos Saavedra, Hinojosa, Menéndez Pelayo \& y los de la hermandad). Espero que tú, ya que no colaboras, nos ayudes. Porque nos hemos comprometido a enviar trabajos y diez duros, si la impresión lo requiere. Aunque sea invitarte por un sablazo, no quiero dejar de hacerlo, pues me figuro que te ofenderías, si no contásemos contigo para eso, ya q. hasta Giner de los Ríos se compromete a aflojar la cantidad, por no poder ofrecer Trabajo.

A los q. estamos en activo se nos exije [sic] diez duros y artículo por barba. Tú te libras, por estar de reemplazo, de ofrecer artículo.

Díme qué te parece la Revista este año. A estas horas quizá la hayas recibido. Si no, mañana.

Contéstame para q. yo comunique a Saavedra las adhesiones.

Saluda afect. a tu señora y $[. .$.$] de tu amigo q. te quiere$

Julián Ribera

Zaragoza 23 Enero 903

¿Cuándo vienes por acá? 
Querido amigo Pascual:

Recibidas tus dos cartas. No te escribí antes esperando que tu espíritu se tranquilizara, pues todo suele ser muy transitorio en la vida: los placeres y los dolores. No hay que decir corr cuánto gusto te vería por aquí y cuán agradable sería para los curitas el charlar contigo y consolarte si necesario fuera \& \&.

Mi mujer se va reponiendo muy poco a poco; apenas se levanta unas cuantas horas al día y durante ese tiempo sin salir de la habitación donde se halla la estufa. El chico q. ha tenido pulmonía tampoco adelanta rápidamente, pero tampoco va atrás; si viene la primavera y hace buen tiempo espero que se restablezca completamente.

En cuanto a lo del homenaje a D. Francisco, podrías tú escoger algún cuentecito inédito, aljamiado, de los q. pueda haber en la Biblioteca Nacional. Eso no es difícil y sería tal vez de buen efecto, sin meterte en muchas historias, transcribiéndolo cuidadosamente y eligiendo uno que merezca ver la luz pública. Si yo estuviera por ahí, iría contigo a ayudarte.

Las oposiciones, según me dicen, es posible que se verifiqquen a fines del mes de Febrero o mediados de Marzo, cuando Eguilaz el de Granada se halle en disposición de arrostrar las fatigas de un viaje y el soplo del Guadarrama. De manera q. si vienes tú nos veremos antes y si por obstáculos de negocios tuyos no vienes, yo iré a verte.

No hace falta tan deprisa los gastos del Homenaje. Ahora están tratando de eso con mucha parsimonia \& \&.

He comunicado lo comunicable con los amigos y todos conforme en desearte mejores días; y si en mi mano estuviere, la felicidad reinaría a tu alrededor. De mi no hay que decir; es demasiado vieja nuestra amistad para que me olvide de nada.

Y te abraza afectuosamente tu siempre e invariable amigo

Julián Ribera

A tu señora, lo que quieras. Adios 
[Anotación con letra de Menéu: Cuatro medias cañas para]

Querido amigo Meneu:

Recibí tu apreciable; no he contestado antes porque he tenido mucho quehacer; baste decirte que después de recibida he tenido que ir a Madrid para el asunto de la Escuela.

Puede decirse que ésta se hará; no sé si las condiciones que he propuesto se cumplirán o no todas; parece que están bien dispuestos. Hasta que no estemos todos allí, no comenzarán los trabajos en serio.

Yo estoy ocupado preferentemente en la construcción de la casa, para tenerla habitable el dia que me vaya. El Huerto lo tengo comprometido para un comprador que no parece, pues está de viaje. Supongo que la venta se realizará antes del 15 de Setiembre; pero me choca que todavía no aparezca; de modo que para entonces te diré lo que haya. En todo caso antes del veinte te escribiré. $Y$ muchas gracias por tus atenciones.

Yo no sé nada de la Revista, hace mucho tiempo. Si el original lo han mandado allá, supongo que no lo tirarán hasta que lo corrijas. Puedes estar descansado, que tomarán precauciones para que no salga con erratas. Y más de árabe.

La casa mía adelanta mucho. Esta semana quedarán terminadas las cuatro habitaciones más precisas; a la otra las siguientes. No quiero que queden albañiles trabajando en mi ausencia.

Saluda afectuosamente a toda la familia y sabes que te quiere tu amigo de siempre

$\underline{\text { Julián Ribera }}$

Puebla Larga 5 de Sete. 904.

14

Puebla Larga 15 Sete. 904

[Anotación con letra y rúbrica de Menéu:

Se le dejó la cantidad que necesitaba al 5 por ciento de interés, y pagó capital e intereses. Pascual Meneu] 


\section{Querido Pascual:}

Recibí tu grata del 7 y recibo con ella también la satisfacción de la enhorabuena q. me das. Todos estamos de enhorabuena. Yo le puse al Ministro una lista de personas aficionadas, indicando las obras que han escrito y lo q. han hecho: no tuve olvidos voluntarios; dejé, sin embargo, como no podía menos, que haga él la elección del personal. Veremos lo que saco.

Mis chicos siguen igual: uno de ellos amenazado, muy amenazado. Por eso mis prisas en la obra: pero también por eso se hacen los remolones los compradores de mi huerto. Hay uno que me ha dado el precio q. yo pedia; pero exije (sic) que le de carretera, antes de hacer la compra. Yo le digo que le daré el dinero que valga el trozo que hay q. expropiar, con tal que éste no valga más que el precio porque yo vendo. Con unas jeringas y otras me entretiene. Hay otro que fue bajando de cinco en cinco mil reales, y cuando ya quedamos a punto, aún tuvo la desvergüenza de pedir una rebaja de otros cinco mil: me quemé y lo mandé a escaparrar.

Ellos han olido que me voy a Madrid; que tengo prisa de resolver; y ¡los judios! esperan q. al fin ceda a sus bicherías.

Mi hermano me ayuda hasta el extremo de pagar todo lo q. hay pendiente, sin faltar una peseta; pero me quedaré debiéndole a él una buena cantidad, proximamente tres mil duros. Esto me ata un poco, porque icómo en esa situación al venir la naranja, puedo yo ser independiente para venderla o no al precio q. él marque? Yo tendré este año, de escasa cosecha, unas diez mil o doce mil arrobas; un real más o menos, resulta de consideración. Para verme libre y desembarazado me conviene el q. me dejes la cantidad q. tienes en el Banco de Castellón. ¿Podrias ir a Valencia el día 20 y allí realizar el préstamo? Estoy dispuesto a hacerlo en la forma que desees; si en documento privado, en documento privado; si en documento público, público.

Lo que deseo sí, es que el interés no sea subido, sino decente, y que el préstamo a devolver dentro de tres o cuatro años. En el documento se dirá que si yo puedo devolverlo a los dos meses, o a los tres, que pueda hacerlo. (Pues no cejo en vender el huerto, con buenas condiciones para no estar con deudas.)

En tres años podré pagarlas, creo; pero quiero q. sea antes, cuanto antes, es más desembarado. A mí me conviene ahora tener movilizada mi hacienda. Si estás dispuesto a ir a Valencia con la cantidad el dia 20, dímelo señalando hora y lugar de cita. Yo iré en correo, q. llega a las diez de la mañana. Saluda a tu familia y $[\ldots .$.$] de tu amigo$ 


\section{Querido amigo Pascual:}

Hace cuatro dias, creo, te escribí, pidiéndote una entrevista en Valencia, a donde debía haber ido ayer (y no fui a causa del temporal que por aquí reinó). No he recibido contestación.

El Domingo por la tarde me voy a Madrid; me espera el Ministro de Instn. Pública, para ultimar los detalles de la Escuela. Desearía, para entonces, tener acabados mis asuntos de acá y marcharme sin graves preocupaciones.

Dime cuándo y dónde podré verte, con el menor gasto de tiempo posible; pues una hora de ausencia de aquí la debo evitar, si puedo. La obra se está terminando; son los días en que a cada minuto hay que decidir lo q. hay que hacer \& \&. Te agradecería contestación pronta, y aún telegráfica, si hay posibilidad.

Perdona las prisas; pero se han pasado cuatro o cinco días sin entendernos. Tuyo afmo. amigo Julián Ribera

(Hoy 21)

16

Amigo Meneu: Recibí tu carta; si se han firmado las paces, sea enhorabuena; con tal de q. te dejen suelto, sin el compromiso del pleito; con libertad, y sin ese fardo, ya es bastante mejora. Si se han cerrado con ese documento, todos pleitos posteriores, puedes cantar gloria. Era un abismo de abismos, el sitio en q. te encontrabas. amigo

El viernes por la mañana llegaremos a Madrid. Ya te abrazará tu afmo.

Ribera

Querido amigo Meneu: Enhorabuena por tan feliz nueva si efectivamente queda el asunto del pleito resuelto para siempre. Estaba esperando la certificación para contestarla, pero todavía no ha llegado y aprovechando el que 
le escriba mi padre le pongo estas líneas como avance del abrazo que pienso darle por tan felicísimo acontecimiento de las paces.

Me están esperando para el correo. Adiós su amigo que le quiere

Julián 